Volume 14

Number 12014

December 2014

\title{
A Biblical Approach to Cadaveric Organ Transplants
}

Erica Graham

Cedarville University, EricaCGraham@cedarville.edu

DigitalCommons@Cedarville provides a publication platform for fully open access journals, which means that all articles are available on the Internet to all users immediately upon publication. However, the opinions and sentiments expressed by the authors of articles published in our journals do not necessarily indicate the endorsement or reflect the views of DigitalCommons@Cedarville, the Centennial Library, or Cedarville University and its employees. The authors are solely responsible for the content of their work. Please address questions to dc@cedarville.edu.

\section{Recommended Citation}

Graham, Erica (2014) "A Biblical Approach to Cadaveric Organ Transplants," CedarEthics: A Journal of Critical Thinking in Bioethics: Vol. 14 : No. 1 , Article 4. 


\title{
A Biblical Approach to Cadaveric Organ Transplants
}

Browse the contents of this issue of CedarEthics: A Journal of Critical Thinking in Bioethics.

\begin{abstract}
Upon passing their driver's license exam every American has the opportunity to become an organ donor. Organ donor status allows immediate retrieval of transplantable organs after death for transplantation into other patients in order to save their lives. Many citizens endorse this action because one donor can save multiple lives by donating viable organs postmortem. However, some people do not endorse organ transplants arguing that it violates the body and that being an organ donor results in a premature declaration of death.

The current standard for cadaveric transplantation is retrieval from heart beating donors. A heart beating donor is brain dead with circulation artificially maintained by a ventilator. The ethical permissibility of this standard is questioned by some Christians. Christians do not believe in a bodily resurrection which provides one basis for permitting organ transplants. Christians also view the body as having intrinsic worth because of the presence of the image of God. When one views bodies as having intrinsic worth organ donation becomes a natural logical conclusion supported by stewardship and loving others (Richards, 2012). While there is nothing inherently wrong with giving of receiving cadaveric organs ethical discussions still remain. Transplantation of cadaveric organs raises ethical questions about the dying process, defining death, and bodily integrity (Ramsey, 2002).

The best way to evaluate these ethical issues is by establishing a Biblical framework through which to consider and evaluate them. This paper will perform that task, ultimately arguing for the support of cadaveric transplants by Christians as an exercise of stewardship practiced in a way that maintains the sanctity of life.
\end{abstract}

\section{Keywords}

Ethics, Biblical ethics, organ transplants, organ donor, Christians

\section{Creative Commons License}

(1) (1) $(3)$

This work is licensed under a Creative Commons Attribution-Noncommercial-No Derivative Works 4.0 License.

Follow this and additional works at: http:// digitalcommons.cedarville.edu/cedarethics

Part of the Bioethics and Medical Ethics Commons 


\title{
A Biblical Approach to Cadaveric Organ Transplants
}

\author{
Erica Graham \\ Cedarville University
}

\section{Introduction}

$\mathrm{U}$ pon passing their driver's license exam every American has the opportunity to become an organ donor. Organ donor status allows immediate retrieval of transplantable organs after death for transplantation into other patients in order to save their lives. Many citizens endorse this action because one donor can save multiple lives by donating viable organs postmortem. However, some people do not endorse organ transplants arguing that it violates the body and that being an organ donor results in a premature declaration of death.

The current standard for cadaveric transplantation is retrieval from heart beating donors. A heart beating donor is brain dead with circulation artificially maintained by a ventilator. The ethical permissibility of this standard is questioned by some Christians. Christians do not believe in a bodily resurrection which provides one basis for permitting organ transplants. Christians also view the body as having intrinsic worth because of the presence of the image of God. When one views bodies as having intrinsic worth organ donation becomes a natural logical conclusion supported by stewardship and loving others (Richards, 2012). While there is nothing inherently wrong with giving of receiving cadaveric organs ethical discussions still remain. Transplantation of cadaveric organs raises ethical questions about the dying process, defining death, and bodily integrity (Ramsey, 2002).

The best way to evaluate these ethical issues is by establishing a Biblical framework through which to consider and evaluate them. This paper will perform that task, ultimately arguing for the support of cadaveric transplants by Christians as an exercise of stewardship practiced in a way that maintains the sanctity of life.

\section{The Decalogue and Cadaveric Organ Transplants}

When developing a biblical ethic many scholars start at the Decalogue. The Ten Commandments were treated as the substance of Christian ethics in the time of the early church as evidenced by Paul's personal conviction by and multiple references to them throughout the New Testament (Rooker, 2010). It is prudent for modern Christians to follow the norms set by the Apostles in the early church, especially related to determining the foundation of Biblical ethics. The precepts of the Ten Commandments were central to community life in the second century and this paper will use relevant commands to construct a framework for evaluating ethical concerns surrounding cadaveric organ transplants.

The sixth commandment provides a foundational principle to the ethics of cadaveric organ transplant. In Exodus 20:13 God commands "You shall not murder," establishing that he alone is sovereign over life and death and therefore he alone wields authority to terminate life. This prohibition exists because of man's unique value as the image of God (Rooker, 2010). Believing man bears the image of God is an essential concept in all organ transplant ethics since it provides the foundation for stewardship over one's own body as a potential source of organs (Campbell, 
1993). J. I. Packer describes the basic theology of the sixth commandment as regarding human life as holy because it is made in the image of God and is a good gift from God. He later expands on this principle to mean "consistently preserving life and furthering each other's welfare in all possible ways” (2007, p. 78). David Jones interprets sixth commandment theology on a practical level to include taking precautions against the loss of life (2013). Mark Rooker interprets these implications as believing other's lives are important and consequently defending and protecting them (2010). Jones draws these opinions to a conclusion, imploring his readers to develop a mindset of seeking to preserve and respect the sanctity of human life in every area (2013). These theological conclusions not only suggest the permissibility of transplants to maintain life but also provide a central moral norm for approaching the ethics of cadaveric transplants. The sanctity of life is foundational to thinking rightly about all death related issues. Christians must approach cadaveric transplants in a way that maintains the dignity of the donor before and after death. The practical implications of this approach will be explored later.

The eighth commandment builds upon the ethical foundation laid by the sixth commandment. In Exodus 20:15 God commands his people "You shall not steal.” Stealing can be better understood as depriving someone of what is rightfully theirs or taking other's property without permission (Packer, 2007). Deuteronomy 25:16 extends this definition to include all forms of dishonesty (Rooker, 2010). In making this prohibition God's will for his people is "to not have anything that we cannot obtain by honorable means...”(Packer, 2001, p.90-91). Therefore, when retrieving organs one must use honorable means. Any action manipulating a person's situation for another's personal gain violates the spirit of the eighth commandment and should be strictly avoided (Rooker, 2010). An example of such a behavior is taking advantage of one dying person to harvest organs for another person in need of a transplant. Jones interprets the eighth commandment to also prohibit "the misappropriation of anything over which man is a steward”(Jones, 2013, p.186). Man's role as a steward applies to organ transplants because organs are a resource. One exercises wise stewardship when cadaveric organs are used to give life back to the dying rather than left to rot in a grave (Richards, 2012). (The ethical issues surrounding the stewardship of organ distribution will not be discussed in this paper.) The sixth commandment guides stewardship by setting limitations to applying the sanctity of life. God requires justification for invading the body because it is made in his image and also requires respect for the wishes of the individual serving as a donor (Campbell, 1993). This means God forbids stealing organs or taking advantage of a dying person to retrieve organs based on stewardship and the sanctity of life. One can therefore conclude by synthesizing the sixth and eighth commandments that Christians are responsible to defend the life of every person as bearers of the image of God and to appropriately steward resources given. Cadaveric organ transplants are supported by the Ten Commandments as an act of stewardship provided the methods do not violate the sanctity of life.

\section{Two-Testament Interpretation}

The Old Testament contributes to a biblical ethical approach to cadaveric organ transplants by demonstrating how Christians should relate to others in light of the covenant and by demonstrating how they should respect the lives of others. Generally the covenants established in the Old Testament imply two things: first that God has established a love bond with humans, and second that God's people should commit to others as God committed to them (Smith, 1993). As Christians commit to other people because of the covenants, they must do so in light of the 
sanctity of life. The anger God displays against Cain in Genesis 4:8-12 for killing Abel reveals how much God hates when life is disrespected and reinforces the sacred nature of life as revealed in the creation account and the sixth commandment. This concept is not solely reinforced in the account of Cain but appears ubiquitously throughout the Bible. The Old Testament therefore establishes "the sanctity of life and the dignity of death is a right due every human being by our Divine Creator -God, who is the author of all life” (Miller, 1971, p.17). All methods of organ transplantation must show commitment to love others by defending the sanctity of their life.

The New Testament helps Christians develop a proper view of death, reinforces the permissibility of cadaveric transplants, and demonstrates how to properly love others. Cadaveric donation requires understanding if and how sanctity of life applies to deceased persons because the donor is dead. John 10:10 describes life in Christ, arguably eternal life, as life to the full. Life and all of its implications then do not cease at death but become more fully realized upon resurrection. Based on this passage, Miller argues the sanctity of life does not terminate at death because life continues on eternally (1971). A biblical approach to cadaveric donation cannot ignore a proper respect for the deceased person because their life has only ended in the earthly realm. A deceased person's body carries the memory of a life on earth and a shadow of the life continuing on eternally. A deceased body demands respect because disrespecting it disrespects the life it once housed that now lives elsewhere. In 1 Corinthians 15:35-49 Paul establishes the resurrected bodies of Christians as spiritual bodies, not requiring a fully intact body for successful resurrection. Paul's allusion to being martyred in 1 Corinthian 13:3 aids understanding resurrection bodies by demonstrating even a person burned can be raised (Thobaben, 2009). It can therefore be understood that organ transplantation from cadavers is permissible because the life of that person continues on outside of the earthly body which is not required by that person anymore.

In respect to loving others "the crucial Christian duty is to protect the weak" (Smith, 1994, p.14). The death of Christ as described in John 15:12-15 demonstrates complete giving of one's life fully in love to God and to others. Christians should follow Christ's model of sacrificial giving (Thobaben, 2009). This interpretation of Christian duty is supported by 2 Corinthians 5:14-15 in which Paul asserts that Christ died not that believers would live for themselves but for Christ. Living for Christ includes living for others because Christ lived and died for all of humanity. Medical actions are acceptable forms of loving others as Christ loves. In Mark 2:17 Christ compares sinners needing a savior to the sick needing a doctor. His comparison reveals Christ saw attending to other's medical needs as a great sign of love. The New Testament therefore supports organ transplants as not preventing a saved donor from being resurrected and also a proper expression of love as attending to people's medical needs.

\section{Tripartie Moral Event}

Character. Before approaching a discussion of ethical goals and ethically permissible actions related to cadaveric organ transplants, individual character must be examined. The Christian must seek to model Christ's giving and to view all people as sacred because they are made in God's image. Any genuine gift can open and grow the heart of a Christian through the ministry of the Holy Spirit. Christians should actively be giving in all areas of their life to promote their spiritual growth. It is prudent and required of the Christian to give whenever a need is presented and one has the resources to meet that need (Thobaben, 2009). Giving organs is a great act of love that benefits a neighbor after one's death. The deceased's family also can show love to a 
neighbor this way (Campbell, 1993). One must be wary not to give overzealously, developing a godlike attitude. Gilbert Meilaender uses donating anencephalic infants' organs in order to help bring meaning to the child's short life as an example of misusing giving through assuming a godlike responsibility to give the dying child a meaningful life (Meilaender, 2013). Christians should seek to imitate Christ's character of giving but not become God.

In order to properly view others' lives as sacred one must first possess an accurate definition of life. A sound biblical perspective defines life as "the ability to live and function creatively and meaningfully with intelligence and responsibility, and in a spirit of fellowship with the Almighty God" (Miller, 1971, p.21). The concept of a spirit is central to biblically defining life. Spirit is central because "the root of human value lies in the relation to a creator, a relation not dependent on human capacity for awareness" (Smith, 1993, p.13). One must be cautious not to call a dead person alive and vice versa. In order to apply the sanctity of life properly one must be able to tell when a person is dead and when a person is alive. For example, it is misleading to talk about the life of a person who is brain dead and misleading to refer to their vital signs as occurring spontaneously. These distinctions are important for discussing cadaveric transplants because it is futile to ventilate and circulate a corpse unless they are a donor (Ramsey, 2002). The goal section will complete this discussion.

As previously defined, life's value is linked to God and therefore requires respect. Current culture's view of bodily integrity and value continually diminishes. Such devaluing of the body must be avoided within Christinatiy. Simply viewing the body as a source for organs loses the connection between life and the body and raises the temptation to believe a person transcends their body which results in dehumanizing living persons (Meilaender, 2013). "If we wish to avoid being inundated by either horticultural or engineering metaphors, that will depend in great measure on the recovery of a proper sense of the integrity of man's bodily life, as against the Cartesian dualism and mentalism of the modern period which rejoices without discrimination over every achievement or intervention or design which shows that the body is only a thing-inthe-world to be subjected to limitless control” (Ramsey, 2002, p.209). Christians should accept scientific progress provided it does not violate or diminish the sacred value of bodily life. Medical interests of procuring organs must never be allowed to negatively affect thee respect, dignity, and care of a dying person and their family (O'Rourke, 2000). For example, despite the benefits of using persistent coma patients as organ donors, this cannot be allowed not only because of the immense negative affect it would have on culture's view on human dignity but also because a body resisting death, having vitality, deserves respect. A great temptation exists to focus on the greater good of organ transplants and ignore the bodily integrity of the donor.

Societal demands for more organ donors must never override the importance of the body "as the place of personal presence” (Meilaender, 2013, p.96). According to Courtney Campbell, any organ procurement taking place against or irrespective to the donor's wishes violates the imago dei (1993). (Further discussion of how people should become organ donors and issues surrounding coercion are beyond the scope of this paper and will not be discussed further.) Some further argue that organ donation "ignores the existential meaning of the body" (Sheldon, 2014). Based on the sanctity of life, Christians can support this argument only when patients are killed or taken advantage of for organ retrieval. Cadaveric organ transplants do not violate the sanctity of life because a body devoid of life should be respected but not in the same way as a living person (Thobaben, 2009). Cadavers are no longer temples because they are devoid of life, of the spirit that defines and provides meaning for life. This absence permits the removal of organs for 
transplant. Respect for cadavers is still required because respect for the body is irrevocably tied to respect for the life of the entire person (Ramsey, 2002). Christians must never view cadavers as collection of body parts to be harvested and used. Viewing them as such offends the memory of the life and violates the sanctity of life (O’Rourke, 2000). Christians must not only respect the dying but also the memory of their life existing in their body after they have died. Practically one maintains bodily respect through harvesting organs in a way that does not maim the body so a proper funeral still can be held.

Goal. The resulting goal from a proper view of the sanctity of life is to protect it in all circumstances. To reach this goal Christians must defend each person's right to a humane death, hold to a strict definition of death, and prevent unnecessarily prolonging life. Many people fear cadaveric transplants result in a premature declaration of death for the donor (Richards, 2012). As previously mentioned, such an occurrence violates the sanctity of life. The University of Pittsburgh's "Policy for the Management of Terminally Ill Patients Who May Become Organ Donors after Death” exemplifies cadaveric donation failing to provide a humane death for the donor (Meilaender, 2013, p.103-4). This policy applies to a patient who will die irrespective of life sustaining treatment, whose family has agreed to discontinue treatment, and who is an organ donor. Under these circumstances the patient is taken to the operating room where life sustaining treatment is removed and they are prepped for surgery. Then an attending physician notes the time respiratory and circulatory function ceases and waits approximately two minutes for documentation of any one of three electrical heart dysfunctions. The patient is then declared dead and the organs are immediately removed (O'Rourke, 200). This is primarily impermissible because it hijacks the dying process for the purpose of harvesting organs, using people as a means to an end, thus violating the sanctity of life. Identifying a dying patient as an organ donor before making the decision to remove life sustaining treatment is becoming commonplace in hospitals. When this occurs death can become a mere obstacle to organ harvesting and the possibility of that person having a humane death decreases (Meilaender, 2013). One can identify a patient as a donor before death but must not permit such knowledge to affect how the patient dies. Another opposition to protocols like those of the University of Pittsburgh is they arguably do not wait long enough for certainty of irreversible cessation of functioning after removing respirators (O’Rourke, 2000). The University Of Cincinnati College Of Medicine suggests waiting two to five minutes to balance the needs for certainty of cessation of functioning and retaining biological viability of the transplanted organs (Sheldon, 2014). This policy is more conservative and acceptable. Balance must be found between obtaining viable organs immediately after death and not expediting the dying process, removing the humaneness. Holding a strict definition of death assists in maintaining this delicate balance.

Maintaining a strict definition of death not only provides for a humane death but also prevents violating the sanctity of life. A definition of death must be established so procedures maintaining that definition can be supported. Put simply, "life means the functioning of the integrated being or physiological organism as in some sense a whole. Death means the cessation of this functioning” (Ramsey, 2002, p.59). Based on that description, determining death appears to be a straight-forward task, but in practice such a simple definition does not work. Because physical life is a sum of interdependent organ systems the exact moment of death is elusive. Different systems cease functioning at different times making death more of a continuum than an easily identified moment (Ramsey, 2002). Outside organ donor patients this is not a problem because determining the exact moment of death is not necessary. However, in order for organs to be 
useful some biological vitality must remain in them, and therefore also in the donor when they are harvested (Jonsen, 1997). For these reasons, when transplants became a medical reality the definition of death underwent revision. In 1967 the Ad Hoc Committee of the Harvard Medical School recommended brain death as sufficient grounds for declaring death (Richards, 2012). In 1968 the Harvard Report suggested death should be understood as "a permanent non-functioning brain" and multiple tests should be performed to determine cessation of functioning (Ramsey, 2002, p.89). Furthermore, in 1978 the United States Congress created the President's Commission for the Study of Ethical Problems in Medicine and Behavioral and Biomedical Research to develop a national standard for death. Their work resulted in the Uniform Determination of Death Act. This act defines death as one of two conditions: "irreversible cessation of circulatory and respiratory functions" or "irreversible cessation of all functions of the entire brain, including the brain stem” (Jonsen, 1997, p.245-6). These standards were initially widely accepted but recently have come under question because of observed similarities between the brain dead and the living. The University of Cincinnati recognizes four similarities between the living and the brain dead: a beating heart with a perfused body, breathing, functioning vital organs, and capability for somatic growth and reproduction. The main difference between the living and the brain dead therefore is lack of capacity for consciousness (Sheldon, 2014). These complicating similarities are a direct result of the fact that a brain dead body's vital signs are sustained by a ventilator.

In order to have a strict definition of death a strict definition of vital signs must also be established. Ethicists should support physicians' claims that vital signs are only considered vital when they occur spontaneously and not maintained by artificial means. The mechanical ventilator creates the greatest obstacle to defining vital signs and therefore death. The mechanical ventilator was originally created to maintain polio patient's paralyzed lungs so they could make a full recovery. This is still the spirit of the modern intensive care unit: "hope that if the body can be helped through the crisis it will eventually recover enough to carry on alone” (Richards, 2012, p.223). Breathing and a pulse can be sustained solely by a ventilator. The brain, however, cannot be indefinitely artificially sustained. This fact is particularly important for determining when vital signs have truly ceased and life has ended. The brain, lungs, heart and their associated systems depend on each other to produce life, when one ends the cessation of the other two inevitably follows (Ramsey, 2002). Therefore, breathing and a pulse cannot be considered vital signs if they are being sustained solely by a ventilator. Brain death, as defined by the Uniform Determination of Death Act is sufficient to declare a person on a ventilator dead despite the presence of breathing and a pulse. One must be very careful not to confuse brain death with irreversible loss of the potential for awareness. Because the definition of life does not depend on human capacity for awareness, the definition of brain death cannot either. Brain death must be considered the complete death of all brain tissue, meaning the brain can no longer properly stimulate vital organs, not as permanent lack of awareness.

The next aspect of defining death considers when a person's spirit has left because the spirit is essential to life. Philosophers often make a distinction between the death of a person and the death of a body (Richards, 2012). This distinction is useful to make because it reveals when organs can be removed from a donor. A lack of vital signs indicates the departure of the spirit and complete cellular death marks complete biological death. After the spirit has departed organs can be removed. It is then ethically permissible to consider a patient dead when spontaneous vital signs have ceased. It would be prudent, however, to wait two to five minutes after disconnecting 
a mechanical ventilator before declaring a patient dead and proceeding with organ procurement procedures. Waiting helps determine absolutely irreversible cessation of spontaneous vital signs. Waiting for two to five minutes and performing multiple tests to confirm brain death is essential because in order to prevent violating the sanctity of life, a clear and certain definition of death and strong legal boundaries for protocols must be maintained (Thobaben, 2009). This means Christians have a responsibility to ensure medical personnel check every reasonable way to determine death before transplanting proceeds (Miller, 1971). The current standard for cadaveric donation as mentioned in the introduction should not be endorsed because irreversible cessation spontaneous vital signs cannot be absolutely determined while a patient is on a ventilator. Some oppose strict regulations because they slow the process of cadaveric donation but one must hold fast to all procedures giving certainty of death to protect the sanctity of life. Accompanying the consideration of mechanical ventilators obscuring the moment of death is a question of when the ventilator is helping a body recover and when it merely circulates a corpse. After brain death is determined the body is merely a corpse being circulated. A body at this point has no hope of regaining independent function and cessation of life sustaining treatments should follow.

The sanctity of life requires not inducing or accelerating death and not using unreasonable efforts to put it off (Miller, 1971). The Church of England provides an acceptable model for identifying and approaching extraordinary means. They believe life should only be sustained in order to keep vital organs alive to determine if spontaneous independent function will ever be restored and if the person will eventually regain autonomy (Ramsey, 2002). Christians should model the Church of England's approach to life-sustaining treatment. Within independent situations it can be determined how long ventilation is provided based on the wishes of the family. It is ethically permissible to continue ventilation in order to maintain organ viability for transplant provided it does not interfere with the family's ability to say goodbye and to properly grieve (Thobaben, 2009). Loving the family members and respecting the dying person's life needs to be the primary goal of end of life care.

Conduct. During the course of any moral event a Christian's conduct should conform to the moral norms established by the Decalogue and the Bible. In cadaveric organ transplants Christians must conform to the sanctity of life as established by the sixth commandment and loving others as demonstrated throughout the Old and New Testaments. In determining how to act one must recognize that any sound ethic will recognize some actions as impermissible regardless of benefits they could produce. Christians must recognize that "certain ethical standards cannot be compromised even for the sake of relieving suffering and death" (O'Rourke, 2000). Based on the sanctity of life, premature declarations of death and actions disrespecting the dying and their families should be resisted by Christians.

Retrieving organs before death occurs is wholly impermissible. Doing so violates the sanctity of life. Many people raise the question as to whether the prohibition against killing could be lifted only for organ transplant situations. Proponents of this approach argue organ retrieval before imminent death does not make a difference for the donor because they will die regardless of when their organs are retrieved and that more lives can be saved because more biologically vital organs are retrievable (Richards, 2012). This view must be opposed as a direct violation of the sanctity of life which is an absolute standard set by God which cannot be ignored under special circumstances. The sanctity of life requires respecting life as long as it remains. Therefore, cadaveric donation is permissible permitting a strict boundary between life and death is 
maintained (Thobaben, 2009). Christians must oppose any policy removing the dead donor requirement. Christians should also not allow premature declarations of death. This is done primarily by defending a strict definition of death as mentioned in the goal section and secondarily by avoiding conflicting interests of medical professionals. Ethicists virtually unanimously agree no one involved in organ procurement should be involved in end of life care, particularly the decision to turn off a ventilator and the declaration of death (Ramsey, 2002). Physicians also should never care for both a donor and recipient. This protects not only the donors from having their death taken advantage of but also the physician from having conflicting interests between patients.

Creaturely love must also be normative in cadaveric transplants. Multiple relationships must display love during the donation process. First, a physician is covenanted to his patient. The patient-physician covenant exists for the patient's "complete care, not for continuing useless efforts of cure" (Ramsey, 2002, p.134). Abiding by this covenantal relationship in love therefore means a physician only provides appropriate care. A physician is not ethically or morally responsibility to perpetuate a vegetable because his care seeks to restore wholeness (Miller, 1971). This means unnecessarily prolonging life is not required of medical professionals and as mentioned previously is a violation of the sanctity of life. A physician also has a duty to keep company with a dying patient. A conflict of interest, as previously defined, cripples a physician's ability to prevent a lonely death for their patient. "If the sting of death is sin, the sting of dying is solitude" (Ramsey, 2002, p.134). Christians must avoid this situation for a dying patient at all times. Further nuances of the physician-patient relationship will not be discussed in this paper.

Another important group of persons to consider is the dying donor's family. One must be careful to not infringe on their quasi rights to the body or with their grieving process. Christians should strongly endorse considering cadaveric to families but should not force it upon those who perceive it as an intrusion. When a patient dies the family currently has the power to determine if organs can be donated if the deceased made no prohibitions or allowances beforehand. The wishes of the family must never override the wishes of the deceased and the cost of harvesting organs should never be billed to the family (Thobaben, 2009). There are many ethical debates surrounding the amount of power family wishes should wield. This paper does not enter that discussion and accepts the common standard which places the donor's wishes above the family's wishes.

\section{Conclusion}

Cadaveric organ transplants are a tremendous opportunity for Christians to exercise creaturely love to one another and to non-believers. God has given humanity resources to develop transplants to save lives and Christians should embrace progress that upholds biblical principles of stewardship and love. Transplants provide a new use for recently deceased persons and the opportunity to save the life of another human, which is an ultimate expression of love. However, caution must be exercised only to support procedures maintaining a respect for life. The sanctity of life is an immovable standard established by God in the sixth commandment. Maintaining sanctity of life in the process of cadaveric transplants consists of preventing premature declarations of death, ensuring adherence to a strict definition of death, ensuring a humane death and not unnecessarily prolonging life sustaining treatments. Christians should also seek to exhibit love and respect for the donor and their family during the entire process. Recognizing that staying alive is not always the moral trump is essential to ministering to the dying. Being 
thankful for and not worshipping medical progress helps ensure a humane dying process. When Christians demonstrate wisdom and restraint regarding medical advances, like organ transplants, they are “...a different kind of life-giving witness to our world” (Meileander, 2013, p.105). 


\section{Bibliography}

Campbell, Courtney S. “On James F. Childress: Answering That of God in Every Person.” In Theological Voices in Medical Ethics, eds. Stephen E. Lammers and Allen Verhey, 127156. Grand Rapids: Wm. B. Eerdmans Publishing Co., 1993.

Jones, David W. An Introduction to Biblical Ethics. Nashville: B\&H Publishing Group, 2013.

Jonsen, Albert R. “Ethical Issues in Organ Transplantation,” In Medical Ethics. $2^{\text {nd }}$ ed. eds. Robert M. Veatch, 239-274. Sudbury: Jones and Bartlett Publishers, 1997.

Meilaender, Gilbert. Bioethics:A Primer for Christians. $3^{\text {rd }}$ ed. Grand Rapids: Wm. B. Eerdmans Publishing Co, 2013.

Miller, George W. Moral and Ethical Implications of Human Organ Transplants. Springfeild: Charles C Thomas, 1971.

O’Rourke, Kevin. A Primer for Health Care Ethics: Essays for a Pluralistic Society. $2^{\text {nd }}$ ed. Washington, DC: Georgetown University Press, 2000.

Packer, J. I. Keeping the 10 Commandments. Wheaton: Crossway Books, 2007.

Ramsey, Paul. The Patient as Person: Explorations in Medical Ethics. $2^{\text {nd }}$ ed. New Haven: Yale University Press, 2002.

Richards, Janet R. The Ethics of Transplants: Why Careless Thought Costs Lives. Oxford, NY: Oxford University Press, 2012.

Rooker, Mark F. The Ten Commandments: Ethics for the Twenty-First Century. Nashville: B\&H Publishing Group, 2010.

Smith, David H. “On Paul Ramsey: A Covenant-Centered Ethic for Medicine,” In Theological Voices in Medical Ethics, eds. Stephen E. Lammers and Allen Verhey, 7-29. Grand Rapids, MI: Wm. B. Eerdmans Publishing Co., 1993.

Sheldon, Kurt. “Transplant Ethics.” Presentation at The University of Cincinnati College of Medicine, Cincinnati, OH, November 22, 2013.

Thobaben, James R. Health Care Ethics: A Comprehensive Christian Resource. Downers Grove, IL: InterVarsity Press, 2009. 